\title{
IKONOGRAFI RESTORAN DAE JANG GEUM YOGYAKARTA (ORNAMEN LOTUS, PHOENIX, NAGA DAN HUI SEBAGAI ORNAMEN UTAMA)
}

\author{
Ika Indriyani \\ ikaindriyani@isi.ac.id
}

\begin{abstract}
Abstrak
Restoran Dae Jang Geum adalah restoran pertama di Yogyakarta yang menerapkan konsep Istana Korea. Restoran Dae Jang Geum digolongkan dalam specialty restaurant di mana suasana dan dekorasi disesuaikan dengan masakan khas Korea. Penelitian ini mengkaji ornamen Korea beserta makna filosofinya dan menggunakan metode kualitatif dengan pendekatan ikonografi. Ornamen pada restoran bukan lukisan asli tetapi dari kertas yang dilukis. Hal tersebut tidak sesuai dengan yang ada di Korea yaitu dengan dilukis. Hasil penelitian menunjukkan ornamen yang terdapat pada restoran Dae Jang Geum baik dari bentuk, penempatan dan ukuran mendekati dengan ornamen asli Korea tetapi terdapat beberapa ornamen dari luar Korea yang sudah menjadi bagian tak terpisahkan dari ornamen Korea. Warna ornamen pada restoran lebih cerah dibandingkan dengan aslinya. Dari segi fungsi ornamen tersebut hanya sebagai hiasan yang mendukung konsep Korea.
\end{abstract}

Kata kunci : restoran, ornamen, Korea

\section{Pendahuluan}

Restoran Dae Jang Geum adalah restoran pertama yang ada di Yogyakarta tepatnya di Jl. Palagan Tentara Pelajar Yogyakarta. Restoran ini menerapkan konsep restoran bernuansa Istana Korea. Bapak Jang Keun Won (Abdul Nasir) adalah pendiri restoran International Family Dae Jang Geum. Dae Jang Geum dalam bahasa Korea memiliki makna "permata istana". Restoran ini terinspirasi dari seorang tabib yang juga seorang koki istana pada zaman dinasti Josoen. Sehingga kisah ini dibuat film dengan berlatar belakang kehidupan Istana Korea. Nuansa khas istana Korea begitu terasa yang tercermin dari arsitektural, system pelayanan, ruang, ornamen serta aksesoris yang mendukung konsep restoran Korea.

Pengunjung restoran Dae Jang Geum adalah kalangan menengah atas terutama cocok sebagai restoran keluarga yang sesuai dengan konsep restoran tersebut yaitu International Family Restaurant dan specialty restaurant. Specialty restaurant yaitu restoran yang suasananya dan dekorasi seluruhnya disesuaikan dengan tipe khas makanan yang disajikan atau temanya. Restoran-restoran semacam ini menyediakan masakan Cina, Jepang, India, Italia dan sebagainya. Pelayanannya sedikit banyak berdasarkan tata cara negara tempat berasal makanan spesial itu. Pengunjung menegah ke atas lebih bisa menerima makanan khas Korea yang rasanya berbeda dengan cita rasa Indonesia. Menu 
Japanesse, Chinesse, serta Indonesian food dan interiornya pada restoran Dae Jang Geum hanyalah sebagai sajian pendukung suasana Korea (Marsum,1993:11).

Dae Jang Geum menarik untuk diteliti karena Dae Jang Geum tidak hanya mengandung unsur-unsur kebudayaan Korea saja tetapi ada Jepang bahkan sedikit unsur Jawa yang diterapkan pada ornamen interior, furnitur, elemen pembentuk ruang, menu masakan dan sistem pelayanan. Restoran ini belum pernah diteliti sebelumnya dari segi ornamen interior dan eksterior. Sehingga menambah khazanah pengetahuan kita tentang tata ruang dan ornamen Korea dan Jepang. Material ornamen dilukis diatas kertas kemudian ditempel pada Tiang yang menyerupai kayu yang sebenarnya adalah besi yang difinishing motif kayu. Sedangkan di Korea dilukis langsung pada balok kayu.

Penelitian ini bertujuan untuk mengetahui bagaimana ikonografi restoran Dae jang Geum yang mengadopsi tata ruang Korea dan Jepang beserta maknanya. Metode penelitian yang digunakan dalam penulisan ini adalah metode penelitian kualitatif dengan pendekatan ikonografi. Metode penelitian kualitatif merupakan metode yang digunakan dengan cara menjabarkan. Ikonografi merupakan studi yang menggali makna dari suatu ikon, sesuatu yang tergambarkan dan terlihat, bisa ditangkap oleh mata, dimana kajiannya mengacu pada upaya pemahaman makna-makna dengan tujuan untuk mengidentifikasi, menggolongkan dan menjelaskan objek-objek visual yang menjadi kajiannya (Mayangsari, Sriti : 2008).

Terdapat 3 tahapan ikonografi menurut Erwin Panofsky, yaitu tahap pre-ikonografi, ikonografi, dan ikonologi. Tahap pre-ikonografi merupakan tahap untuk mengidentifikasi suatu objek. Tahap ikonografi merupakan tahap untuk mengidentifikasi makna sekunder yang diangkat oleh sebuah gambar. Tahap ikonologi merupakan pemahaman mengenai makna intrinsik yang terdapat pada sebuah objek (Panofsky, Erwin : 1939).

\section{Temuan dan Pembahasan}

Dilihat secara umum restoran Dae Jang Geum menerapkan ornamen Korea, Jepang dan Cina dalam elemen pembentuk ruang dan aksesorisnya. Ruang tersebut adalah main hall, VIP, dapur, tatami dan fasad restoran. Pada kajian ini dipilih ornamen yang banyak menempati bagian interior maupun eksterior restoran.

\section{Ornamen Restoran Dae Jang Geum}

\section{Lotus \\ Preikonografi}

Ornamen gambar 1 adalah gambar yang terletak di dapur bagian depan dan seluruh atap main hall. Ornamen ini merupakan ornamen terbanyak yang berada di restoran Dae Jang Geum. Ornamen ini di lukis diatas kertas yang ditempel pada kasau atap berbentuk pipa. Kita dapat melihat pada gambar 1 tengah atas, ornamen bentuk bunga pada kasau tengah restoran hampir sama dengan aslinya. Kita dapat melihat pada gambar 1 literatur kanan bawah. 
Perbedaanya bagian kelopak bunga yang ada direstoran menggunakan warna merah muda, sedangkan warna yang ada pada literatur menggunakan warna merah tua. Warna ornamen ini lebih cerah dibandingkan dengan aslinya. Ornamen bunga ini disebut bunga lotus. Ornamen ini ditempelkan pada kertas yang sudah dilukis. Biasanya di Korea langsung dilukiskan di atas kasau kayu.

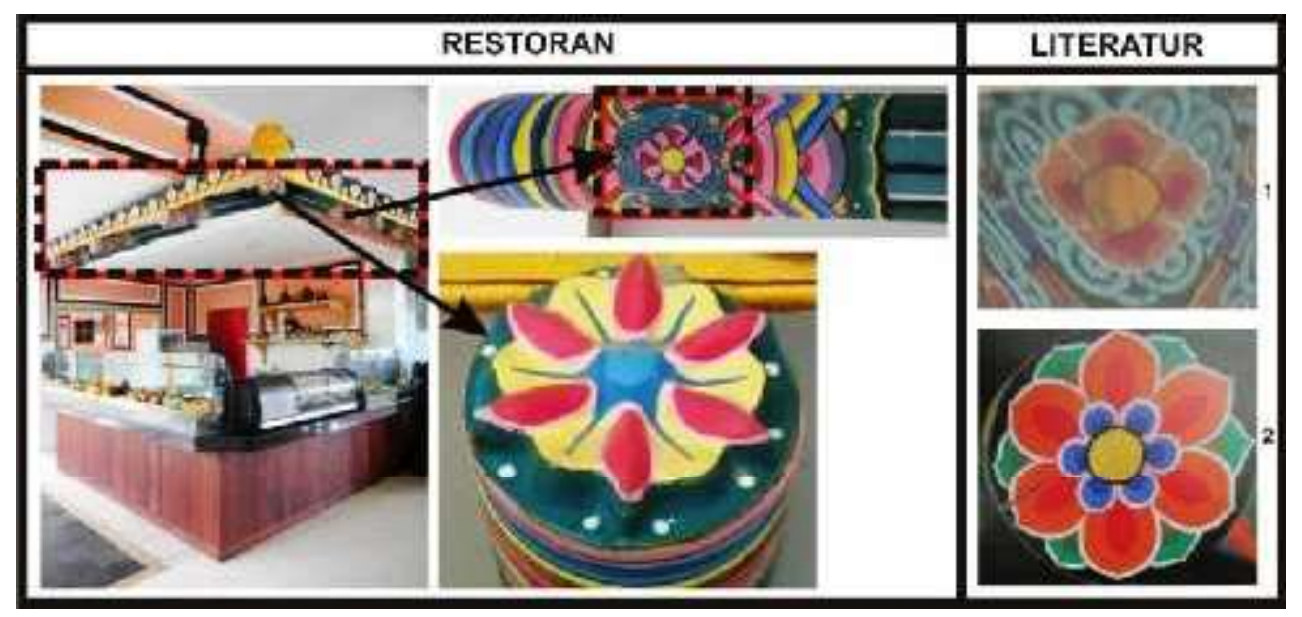

Gambar 1. Bunga Lotus di dapur depan Sumber : Dokumentasi Pribadi, 2015 (kiri) dan Seock Jae, 2005 : 66 (1), Suh, 2009 : 206 (2)

Selain ornamen berbentuk bunga pada bagian kasau tengah, terdapat juga motif bunga pada ujung kasau (lihat gambar 1 tengah bawah). Ornamen ini dapat kita temukan pada gate, kasau main hall dan dapur bagian depan. Ornamen ini dilukiskan langsung pada ujung kasau. Jumlahnya sangat banyak. Pada ujung atap motif bunga terlihat bervolume. Kelopak pertama pada restoran berwarna kuning sedangkan aslinya berwarna biru. Bagian tengah bunga (putik) pada restoran berwarna biru dan aslinya berwarna kuning. Untuk kelopak ketiga menggunakan warna hijau namun terdapat titik-titik putih disela-sela kelopak. Warna ornamen ini lebih cerah dibandingkan dengan aslinya.

Penempatan ornamen ini sama dengan aslinya yang ada di Korea yaitu pada ujung kasau. Ornamen berbentuk bunga tersebut adalah bunga lotus.

Gambar 2 ini penjelasannya hampir sama dengan gambar 1. Ornamen berbentuk bunga ini memiliki banyak kelopak (bagian yang dilingkari dengan gari-garis putus). Warna kelopak terdiri dari merah dan merah muda dengan garis tepi berwarna putih. Putik bunga berwarna kuning. Ornamen bunga ini adalah bunga lotus (gambar 2 no.2). Ornamen bunga kecil berwarna hijau penjelasanya sama dengan ornamen bunga yang terdapat pada kasau (lihat penjelasan gambar 1). Ornamen bunga lotus dengan garis geometris berwarna-warni pada bagian bangunan disebut dengan dancheong. Penempatan yang berada pada sudut atau pojok sehingga disebut dengan dancheong morucho. 


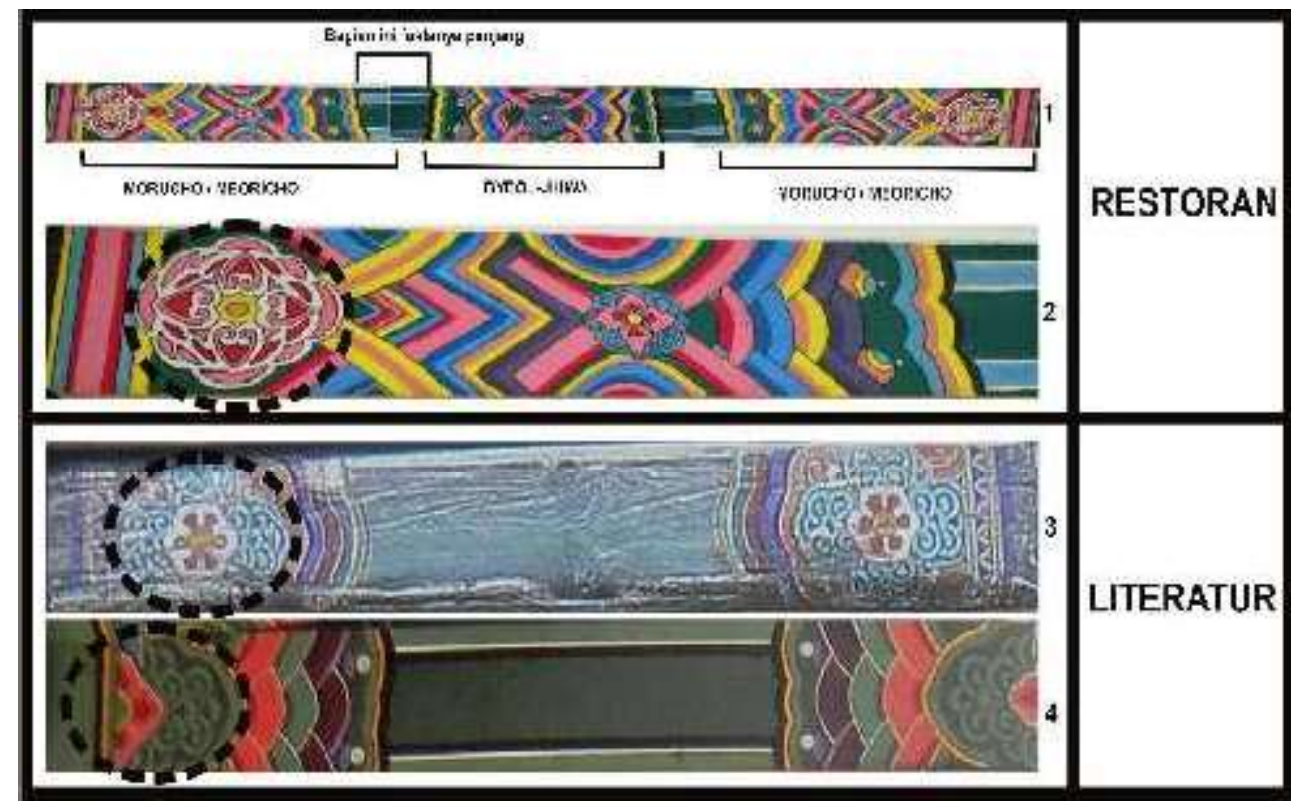

Gambar 2. Ornamen Lotus pada dinding atas main hall Sumber : Survey lapangan 2015 (1, 2), Seock Jae, 2005 : 78 (3), Seock Jae, 2005 : 58

Gambar 3 pada restoran Dae Jang Geum terdapat pada main hall yaitu pada dinding atas yang mengelilingi main hall (lihat gambar 4). Ornamen ini terdiri dari bentuk geometris dan bentuk bunga. Ornamen ini di lukis di atas kertas yang ditempel pada dinding bagian atas main hall, tidak dilukis pada kayu secara langsung seperti pada bangunan Korea. Pada literatur kita dapat melihat isi dari ornamen ini yang bermacammacam seperti swastika, burung bangau, dan bunga lotus (lihat gambar 3 literatur). Ornamen pada restoran ini memiliki isi berbentuk bunga. Bentuk bunga pada restoran hampir sama dengan aslinya (lihat gambar 3 literatur bawah). Bentuk bunga seperti ini adalah bunga lotus. Warna ornamen restoran ini menggunakan biru, merah dan kuning. Kalau aslinya menggunakan warna merah, putih, hijau dan kuning. Warnanya pun lebih cerah dibandingkan dengan aslinya.

Ornamen pada restoran Dae Jang Geum ini sudah mendekati dengan aslinya baik dari bentuk, dan warna tetapi ornamen semacam ini memiliki beragam jenis sehingga yang ada di restoran tidak semuanya ada dalam literatur. Penempatan ornamen yang terletak pada dinding atas hampir mendekati plafon. Hal tersebut sama dengan penempatan ornamen asli, biasanya pada balok bagian atas mendekati plafon. Warna pastel juga diterapkan pada dancheong Korea yang sebenarnya. Dancheong ini di bawa langsung dari Korea oleh pemiliknya sehingga dancheong ini asli. Dancheong semacam ini disebut dengan byeoljihwa. 


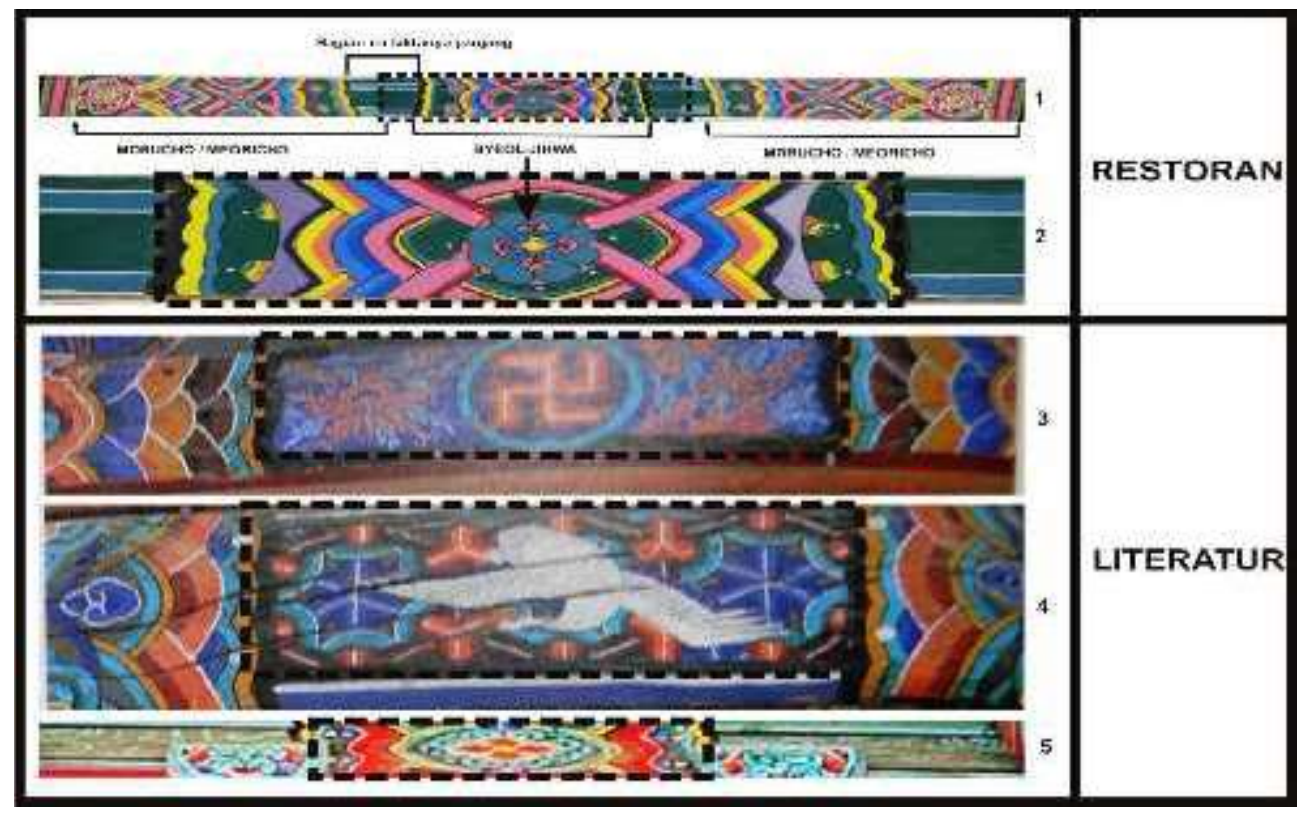

Gambar 3 Ornamen Lotus pada main hall

Sumber : Survey lapangan $2015(1,2)$, Gyun, 2005 : $56(3,4)$,

Korean Culture and Information Service, $2008: 175$
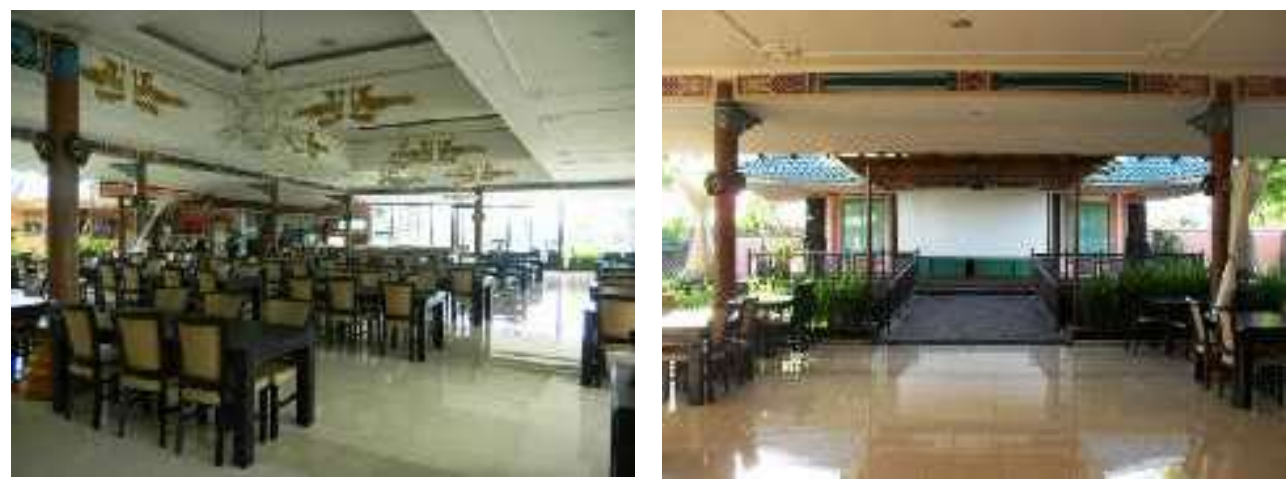

Gambar 4 Ornamen Lotus pada main hall

Sumber : Survey lapangan 2015

Ornamen pada gambar 5 adalah ornamen yang terletak pada ruang VIP. Bentuk dan warna bunga pada restoran mendekati dengan ornamen bunga lotus di Korea akan tetapi pada restoran lebih cerah (lihat gambar 5 literatur). Warna kelopak bagian pinggir berwarna biru, kelopak bagian tengah berwarna merah atau merah muda kemudian putiknya berwarna kuning. Namun putik bunga ruang VIP diganti dengan lampu downlight (lihat gambar 5). Pemilihan lampu downlight tersebut sangat tepat selain sebagai elemen estetis juga sebagai penerangan. Pola warna bunga ini mendekati dengan aslinya. Pada restoran menggunakan kelopak bunga berwarna merah muda dan merah tua sedangkan pada literatur menggunakan warna merah tua dan kuning. Kelopak berbentuk relung pada restoran berwarna biru agak tua sedangkan pada literatur biru muda. Bentuk 
bunga seperti ini adlah bunga lotus. Bunga lotus ini karena berada diseluruh ruang yang menggunakan dancheong sehingga dapat dikategorikan dalam dancheong bidanmunui.

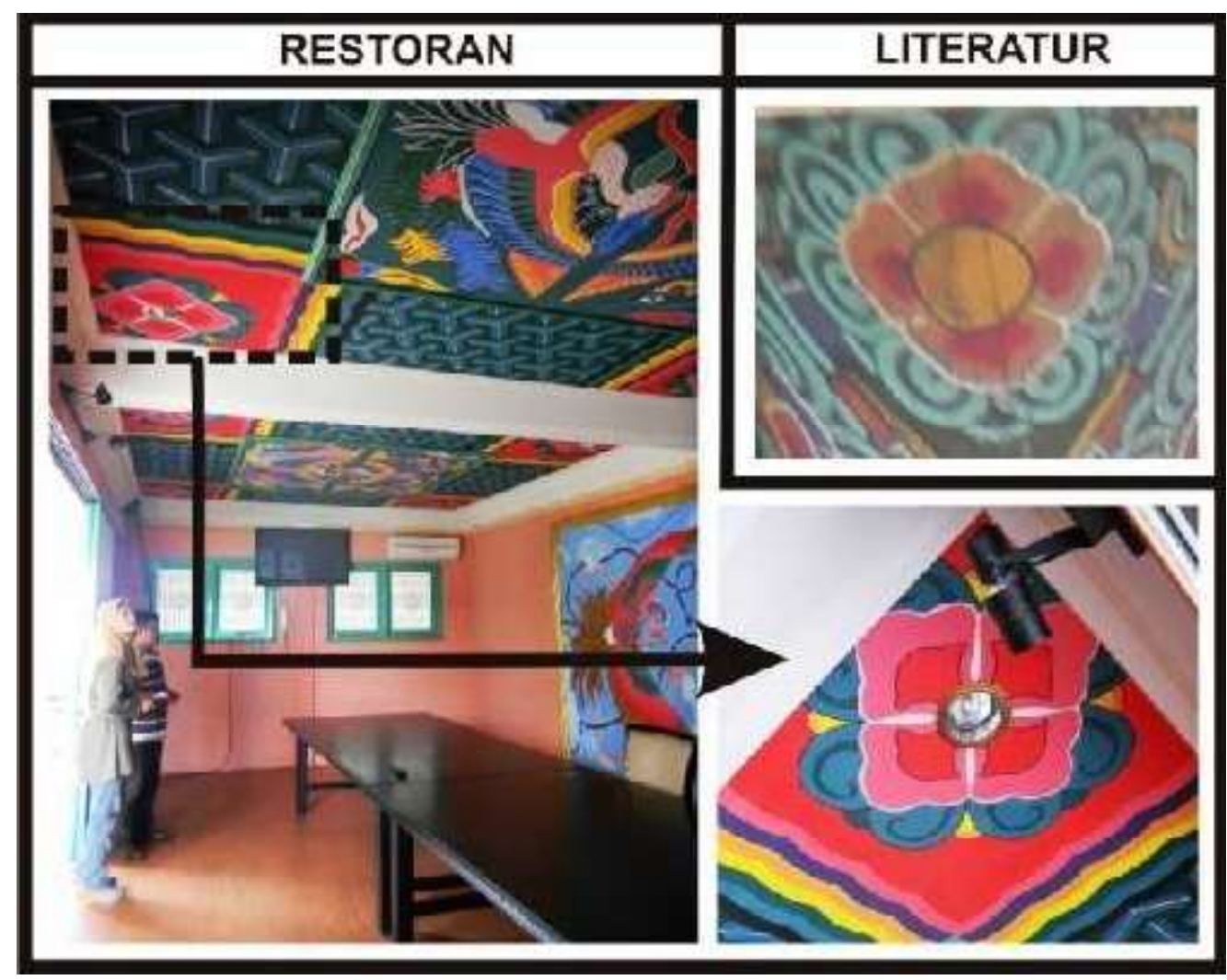

Gambar 5 Ornamen Lotus pada langit-langit ruang VIP Sumber : Survey lapangan 2015 (kanan), Seock Jae, 2005 : 66 (kiri atas)

Ornamen gambar 6 ini terletak pada pagar di luar ruang VIP. Material yang digunakan pada ornamen ini adalah kaca sandblast. Ornamen ini berbentuk bunga yang berada di atas air dengan daunnya yang bulat lebar, bunganya masih kuncup dan terdapat garis-garis gelombang air. Berdasarkan ciri-ciri dari bunga tersebut, dapat langsung kita kenali bahwa bunga tersebut adalah bunga lotus yang tumbuh di air. Jadi ornamen bunga lotus ini baik dalam hal bentuk sudah sesuai dengan aslinya tetapi dalam hal warna berbeda. Ornamen bunga lotus di Korea juga terdapat pada pagar. Lotus ini berfungsi sebagai elemen estetis pada pagar. 


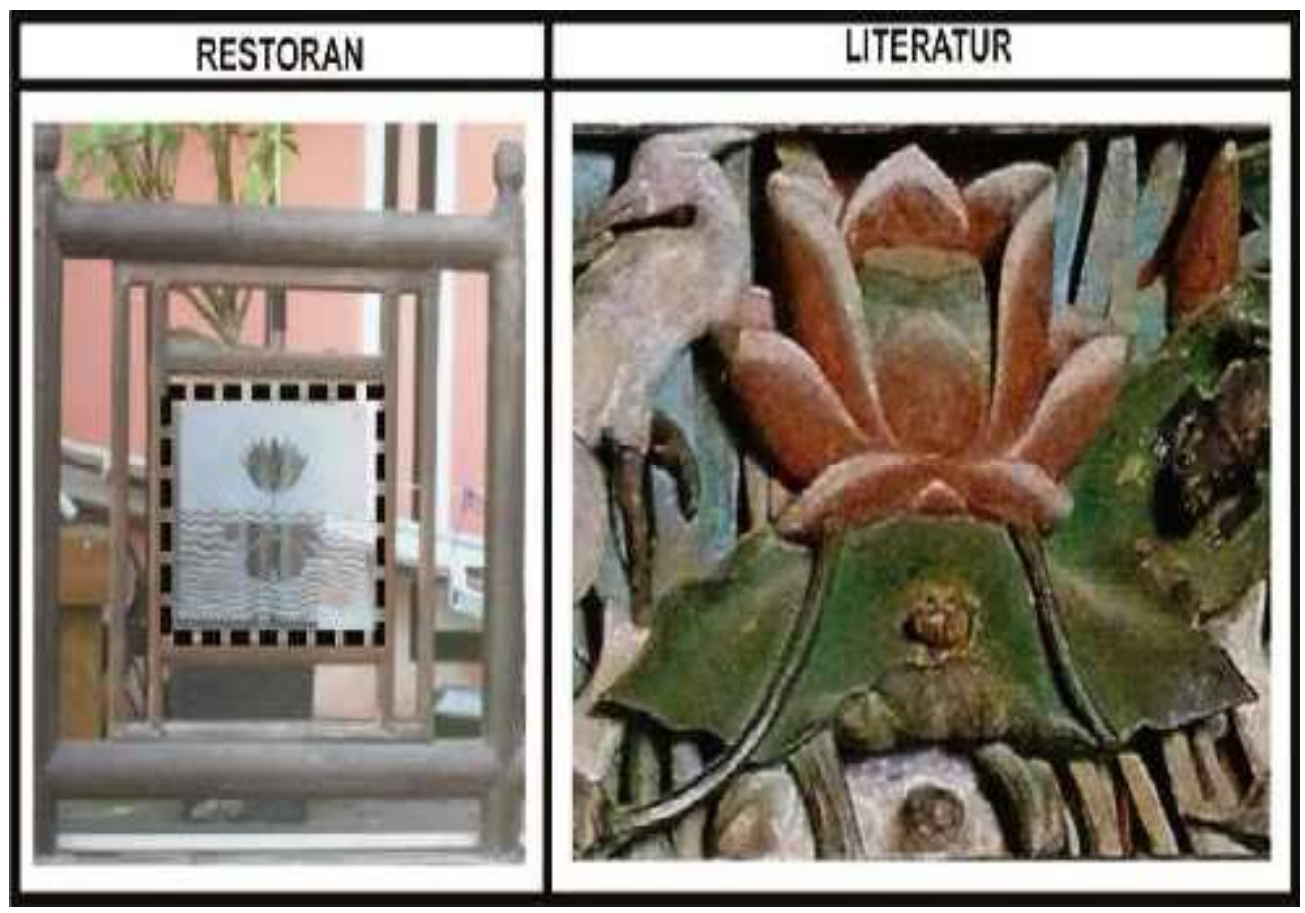

Gambar 6 Ornamen Lotus pada pagar ruang VIP

Sumber : Survey lapangan 2015 (kanan), Gyun, 2005 : 21 (kiri)

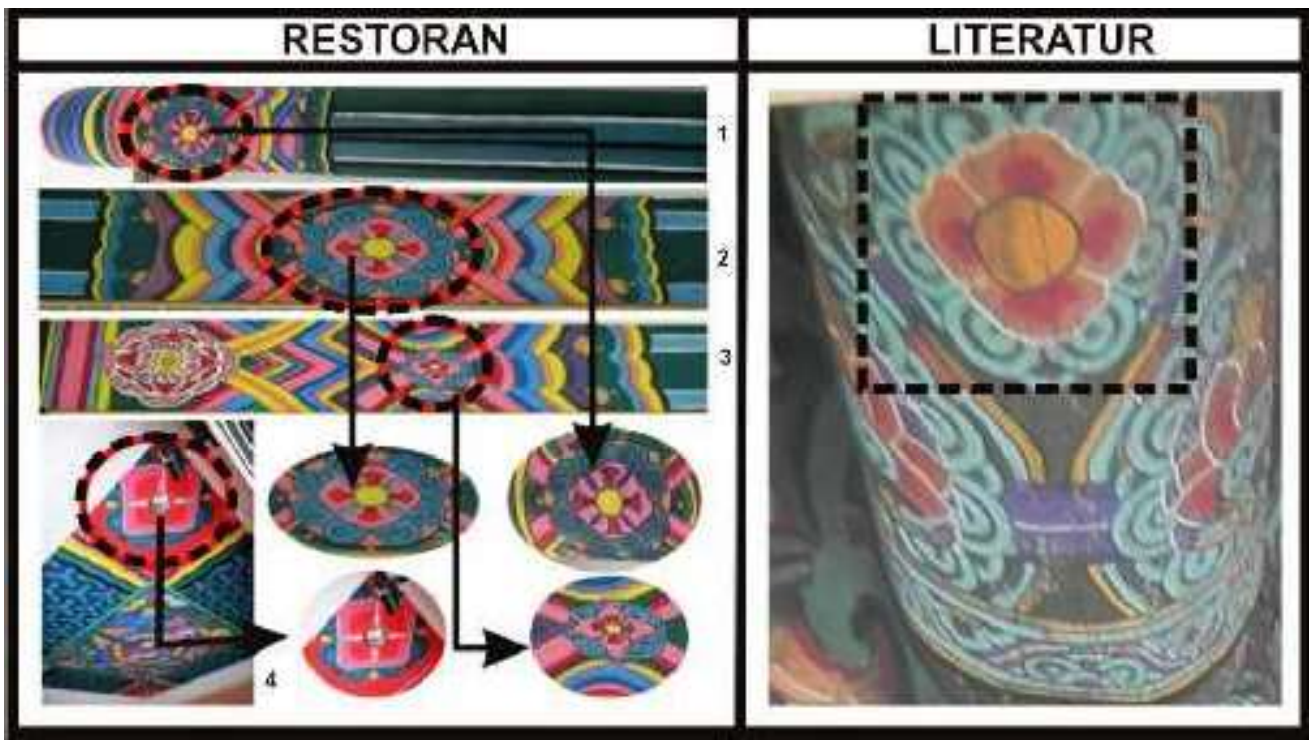

Gambar 7 Ornamen Lotus pada main hall

Sumber : Survey lapangan 2015 (1,2,3 dan 4), Seock Jae, 2005 : 66 (kanan)

Gambar 7 menunjukkan ornamen berbentuk bunga lotus pada seluruh ruang yang menggunakan motif berbentuk bunga lotus. Ornamen ini dapat kita temukan pada main hall dan ruang VIP karena hanya kedua ruang ini yang menggunakan dancheong. 


\section{Ikonografi}

Bunga lotus adalah lotus memiliki simbol kemurnian dan keagungan dan lambang kesuburan atau keturunan berturut-turut. Fungsi dari ornamen ini sebagai elemen estetis pendukung Konsep restoran Korea (Gyun, 2005 : 12).

\section{Ikonologi}

Melambangkan laki-laki dan perempuan, pertanda baik, kebahagiaan (Gyun, $2005: 15)$.

\section{Phoenix}

\section{Preikonografi :}

Ornamen sepasang burung berwarna-warni ini berada pada langit-langit ruang VIP. Hanya terdapat satu ornamen phoenix (tunggal) ini dalam satu bagian ornamen (lihat gambar 8). Walaupun pada langit-langit ruang VIP dibagi menjadi dua dan pada setiap bagian dancheong terdapat sepasang burung seperti ini. Sepasang burung tersebut tersebut dilukiskan diatas kertas yang ditempel pada langit-langit bersamaan dengan awan pada bagian sudutnya. Warna sepasang burung terdiri dari warna biru, putih, hijau, merah, dan kuning. Warna tersebut lebih terang dibandingkan dengan aslinya di Korea yang cenderung gelap. Bentuk sepasang burung ini memiliki ekor yang menjalar kedepan. Ornamen sepasang burung ini di Korea disebut dengan phoenix. Burung phoenix ini merupakan ornamen tunggal pada satu pola dancheong sehingga dikategorikan dalam ornamen dandongmunui. Dandongmunui melibatkan desain tanaman bunga tunggal atau hewan, atau penerapan geometris tunggal atau pola lainnya dalam satu bagian (Korean Culture and Information Service, $2008: 176$ ).

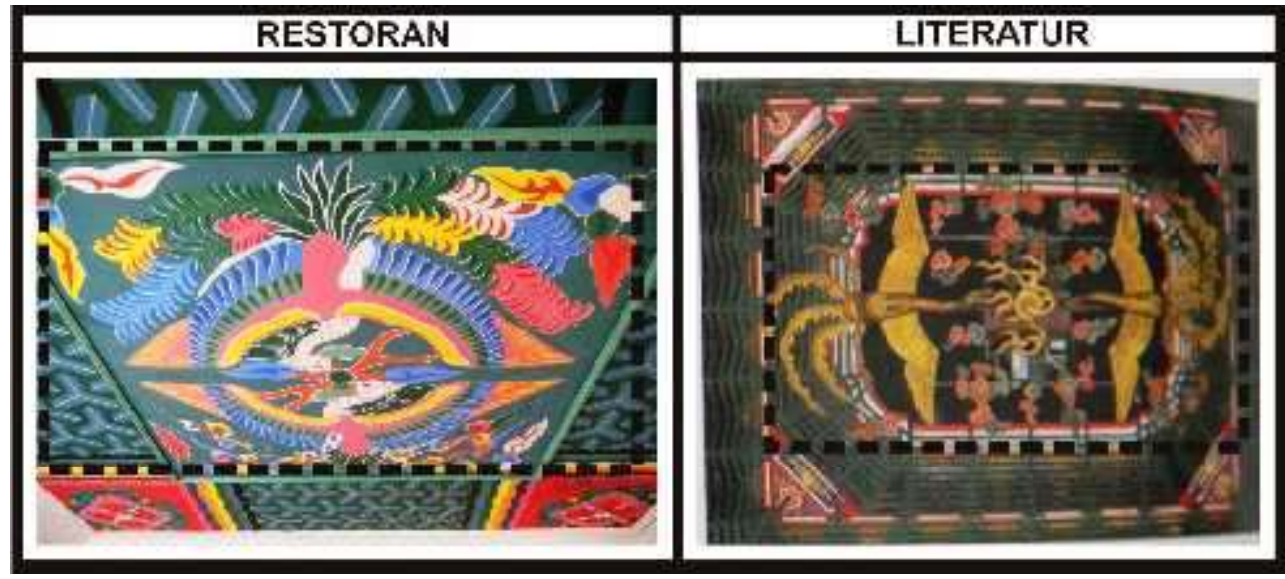

Gambar 8 Ornamen Dangdongmunui berbentuk Phoenix pada ruang VIP Sumber : Survey lapangan 2015 (kiri), Suh, 2009 : 216 (kanan)

Ornamen phoenix juga dapat kita temukan pada main hall (lihat gambar 9). Pada main hall phoenix tersebut berpasangan dan jumlahnya ada 12. Pada bagian bawah 
terdapat daun berwarna emas. Phoenix ini terletak pada langit-langit up ceiling.

Penempatannya pada langit-langit dikaitkan dengan sifat tak ternoda dari phoenix. Warna phoenix ini emas. Material ornamen ini adalah kertas. Fungsi phoenik ini sebagai hiasan.
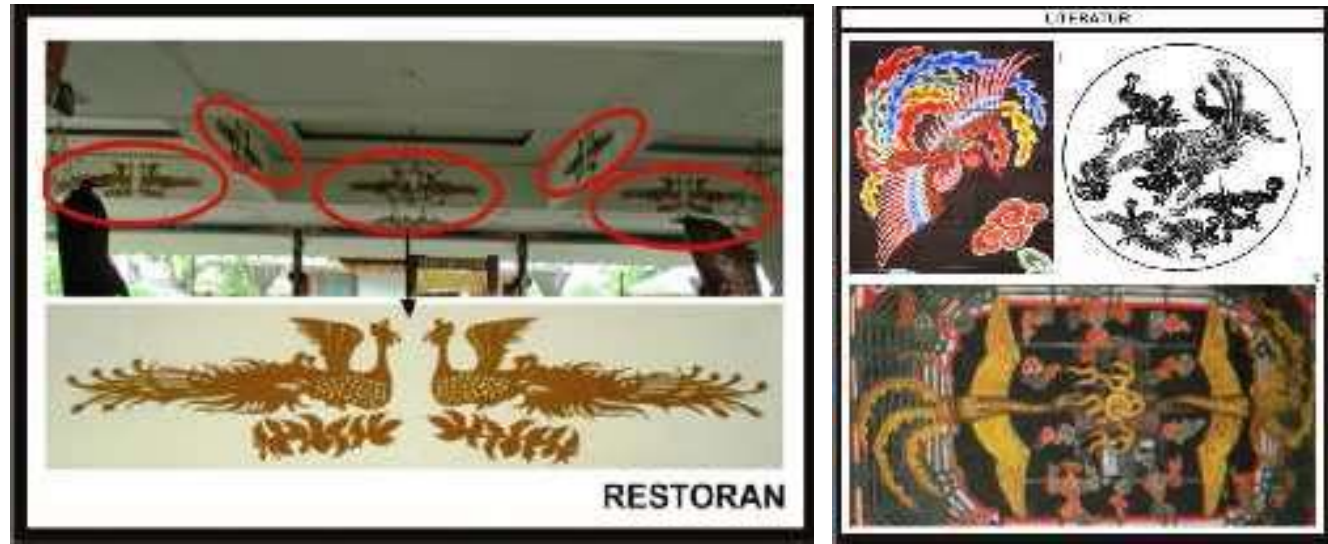

Gambar 9 Ornamen Phoenix Restoran Dae Jang Geum (kiri) dan Phoenix (kanan) Sumber : Survey lapangan 2015 (kiri) dan http://www.unlockingkorea.com (1), Eberhard, 2006 : 290 (2), Suh, 2009 : 216 (3) (kanan)

\section{Ikonografi}

Phoenix melambangkan masa depan yang sejahtera (Gyun, 2005 :137).

\section{Ikonologi}

Burung phoenix dikaitkan dengan sifat tak ternoda. Penampilannya dideskripsikan dan digambarkan dengan keanggunan dan martabat, itu sering dibandingkan dengan permaisuri Dikatakan makan daun bambu, tetapi tidak pernah makan padi-padian atau mati, bahkan ketika sangat lapar. Burung ini biasanya digambarkan tinggal di pohon paulownia, yang dikatakan menjadi tempat bersarang, atau di samping bambu. Burung imajiner ini memiliki leher ular, dagu menelan, dan ekor ikan (www.lifeinkorea.com).

\section{Naga \\ Preikonografi}

Ornamen gambar 10 pada restoran Dae Jang Geum terdapat pada lisplang atap ruang VIP. Ornamen yang terletak pada lisplang ini hanya ditempel begitu saja sebagai hiasan pada lisplang. Ornamen atap ini berbahan gypsum (lihat gambar 10 kiri). Ornamen tersebut tersebut memiliki tiga cakar. Banyaknya cakar biasanya menunjukkan derajat. Ornamen seperti ini yang memiliki banyak cakar dianggap lebih tinggi. Ornamen dengan ciri-ciri diatas adalah ornamen Naga.

Di Korea ornamen naga pada atap ini terbuat dari genteng tanah liat yang difinishing dengan cat warna biru (lihat gambar 10 kanan) dan berfungsi sebagai pelindung erosi kayu dari hujan dan angin). Fungsi ornamen ini pada ujung atap restoran 
Dae jang Geum adalah sebagai elemen estetis pendukung tema Korea pada restoran. Ornamen tersebut pada restoran dengan literatur sama tetapi pada literatur terdapat motif awan tetapi pada gambar literatur 1 dan 2 tidak terdapat ornamen awan (lihat gambar 10 kanan). Sedangkan pada restoran tidak terdapat ornamen awan (lihat gambar 10 kiri).
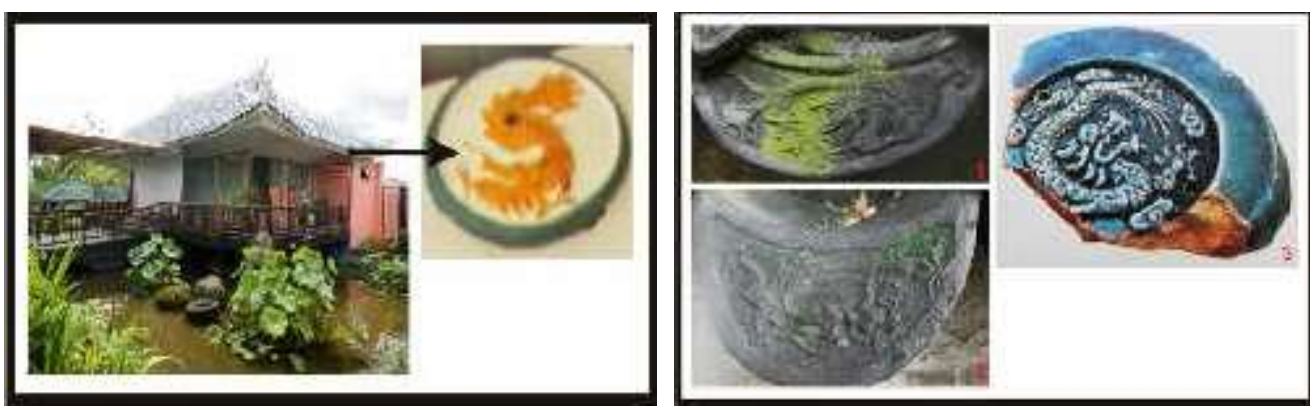

Gambar 10. Ornamen Naga

Sumber : Survey Lapangan 2015 (kiri) dan Suh, 2009 : 222-223 (kanan)

Ornamen naga gambar 11 pada restoran Dae Jang Geum terdapat pada lisplang sushi and sashimi counter. Ornamen yang terletak pada lisplang ini hanya ditempel begitu saja sebagai hiasan pada lisplang. Ornamen atap ini berbahan gypsum dan berwarna emas (lihat gambar 11). Ornamen tersebut tersebut memiliki tiga cakar. Banyaknya cakar biasanya menunjukkan derajat. Ornamen seperti ini yang memiliki banyak cakar dianggap lebih tinggi. Ornamen dengan ciri-ciri diatas adalah ornamen Naga. Di Korea ornamen naga pada atap ini terbuat dari genteng tanah liat yang difinishing dengan cat warna biru dan berfungsi sebagai pelindung erosi kayu dari hujan dan angin). Fungsi ornamen ini pada ujung atap restoran Dae jang Geum adalah sebagai elemen estetis pendukung tema Korea pada restoran.

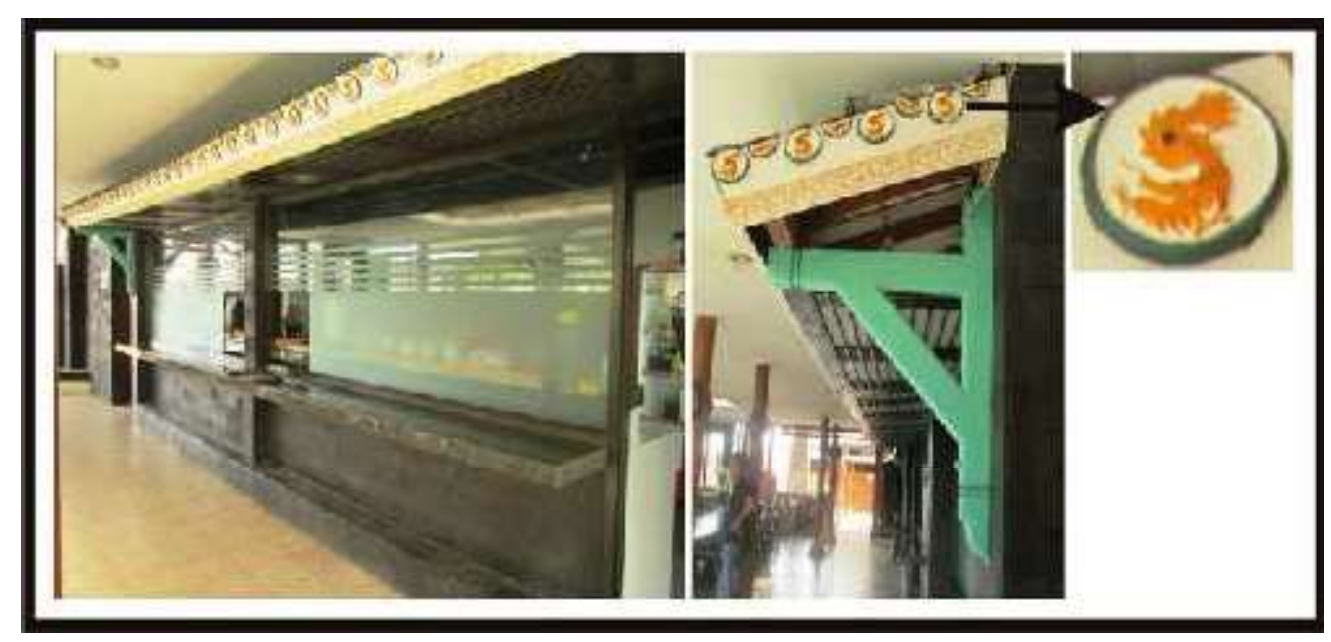

Gambar 11 Ornamen Naga pada Sushi and Sashimi Counter Sumber : Survey lapangan 2015 
Ornamen ini berada di samping genta dan di atas bel terdapat naga kecil yang berkaitan dengan naga yang lebih besar (lihat gambar 12). Pada ujung mulut naga terdapat rantai yang berfungsi sebagai gantungan pembentur bel dari besi yang terlihat seperti kayu. Pembentur tersebut aslinya kayu. Naga tersebut memiliki tiga cakar. Biasanya banyaknya cakar menunjukkan derajat naga. Semakin banyak cakarnya semakin diagungkan. Sosok naga ini terbuat dari besi. Naga ini ditempatkan pada main entrance restoran yang berfungsi sebagai bel restoran yang digunakan pegawai untuk memberitahu pada juru masak apabila ada pesanan baru. Penempatan sosok naga yang berada pada main entrance ini berfungsi juga untuk mengusir roh jahat. Naga pada bel ini di Korea disebut poroe.

Bentuk ornamen naga poroe yang besar yang berada dibel restoran Dae Jang Geum ini biasanya terdapat pada bel kecil di Korea. Untuk naga poroe kecil biasanya diletakkan pada genta besar. Pada gambar 12 bentuk naga Poroe restoran dengan aslinya berbeda karena tidak semua literatur mencantumkan bentuk naga seperti yang ada di restoran Dae Jang Geum.

Ornamen naga pada bell restoran memang tidak mirip dengan literatur karena tidak semua bentuk naga dicantumkan dalam literatur. Pola naga seperti itu biasanya terdapat pada bel kecil di Korea. Jadi pola naga tersebut asli ornamen Korea.

Ornamen naga poroe di Korea diletakkan diatas genta atau lonceng kuil. Kait genta, ditempatkan di atas untuk menggantung lonceng, biasanya berbentuk naga dan karena itu juga dikenal sebagai "naga kait". Naga yang duduk di atas lonceng dikenal dengan nama khusus poroe di Korea. Biasanya terdapat mutiara ajaib didalam mulutnya yang terbuka lebar. Dalam kisah sembilan naga yang mendatangkan keturunan. Poroe adalah anak naga di salah satu manifestasi naga. Sembilan anak naga tersebut adalah Bihui, Imun, Poroe, Pyean, Docheol, Aeja, Gongbok, Sanye, dan Chodo. Paus di laut menakut-nakuti poroe lebih dari apa pun, dan poroe berteriak seperti guntur setiap kali ikan paus berlari ke arahnya.

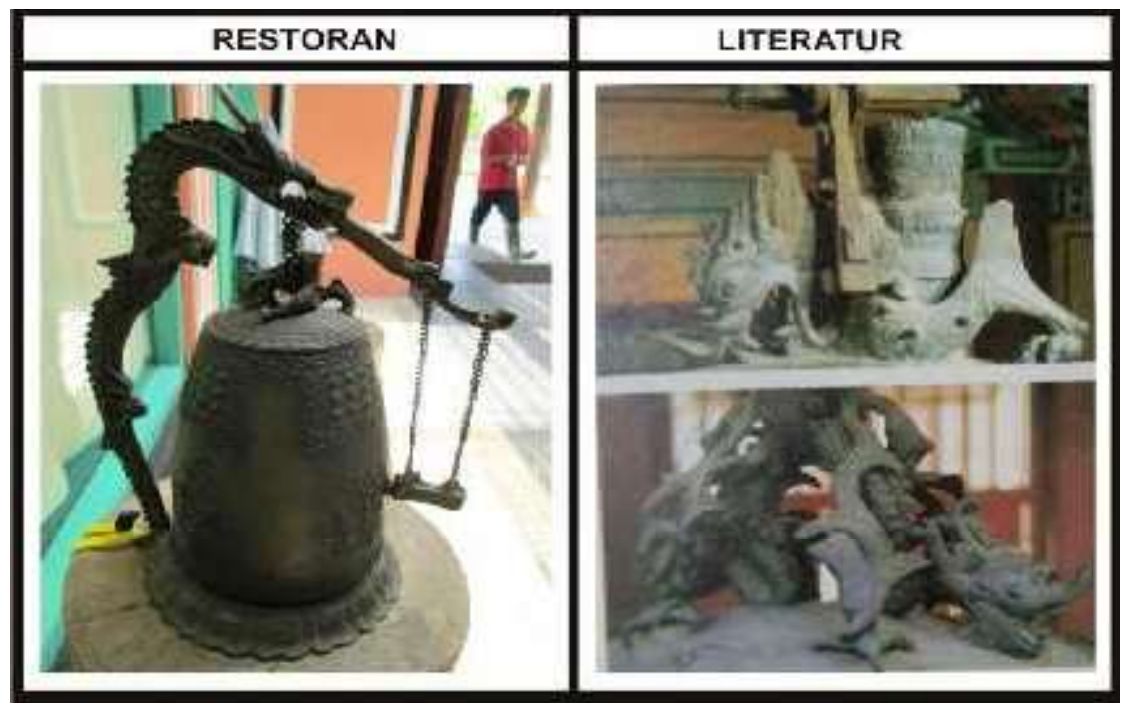

Gambar 12. Ornamen Naga Poroe pada lonceng atau genta Sumber : Survey Lapangan 2015 (kiri) dan Gyun, 2005 : 31 (kanan) 


\section{Ikonografi}

Naga di Korea menyerupai versi Cina tradisional, dengan fitur seperti kepala ular, tanduk seperti rusa, mata hantu, telinga sapi, cakar elang, kaki harimau, perut dan ekor ular yang bau amis. Mereka sering tampil dengan mutiara ajaib di mulut mereka. Disamping kesamaan fisik, sifat dan makna simbolik yang dikaitkan dengan naga berbeda antara kedua negara.

Naga di Korea sebagai lambang kebaikan, kebahagiaan, keuntungan, dan kemakmuran. Naga sering terlihat pada dekorasi kuil dan salah satu yang menempati tempat yang penting di sana. Naga ditemukan di dalam dan di luar Halls Dharma (gambar perumahan bangunan Buddha dan Bodhisattva) di depan pilar, atap, sisi tangga luar, sebagai kanopi di atas altar, langit-langit, interior pilar dan di dinding (Gyun, 2005 : 23).

\section{Ikonologi}

Penempatan ornamen naga pada atap mungkin dikaitkan dengan kemampuan untuk mengendalikan cuaca, menyebabkan awan, kabut atau embun untuk membentuk serta curah hujan mulai atau berhenti.

\section{Simbol Hui}

\section{Preikonografi}

Simbol 亿 terdapat pada seluruh ruang makan restoran Dae Jang Geum dan fasad depan bangunan restoran. Ruang-ruang yang menggunakan ornamen meander adalah sushi and sashimi counter (1,) ruang tatami (2), main hall (3), ruang VIP (4) (lihat gambar 14). Pola liku-liku pada bagian fasad depan restoran ini berwarna merah dengan finishing cat. Pola ini sesuai dengan aslinya (lihat gambar 13).

Pola liku-liku yang lain dapat kita temukan pada ruang tatami, main hall, ruang VIP, sushi and sashimi counter. Peletakkan ornamen ini pada ruang-ruang VIP, ruang tatami dan main hall didinding bagian atas, hampir mendekati plafon. Ornamen $\boldsymbol{乛}$ pada sushi and sashimi counter yaitu pada lisplang atap (lihat gambar 14 kanan atas). Ornamen ini bermaterial gypsum yang dicat warna emas. Ornamen ini timbul. Ornamen 亿 atau liku liku disebut meander. Di Korea ornamen ini disebut hui. Fungsi ornamen hui pada restoran Dae Jang Geum sebagai elemen estetis. Simbol meander pada dinding fasad baik bentuk dan warna sesuai dengan aslinya namun meander pada main hall warnanya berbeda yaitu emas. Pola geometris meander mungkin bentuk tertua dari desain dalam sejarah manusia. Sejak awal, mereka tampaknya telah membawa makna spiritual. Ornamen meander banyak ditemukan dalam seni Yunani dan Romawi. Dalam Yunani Kuno ornamen ini muncul pada banyak arsitektur dan tembikar (vas). 


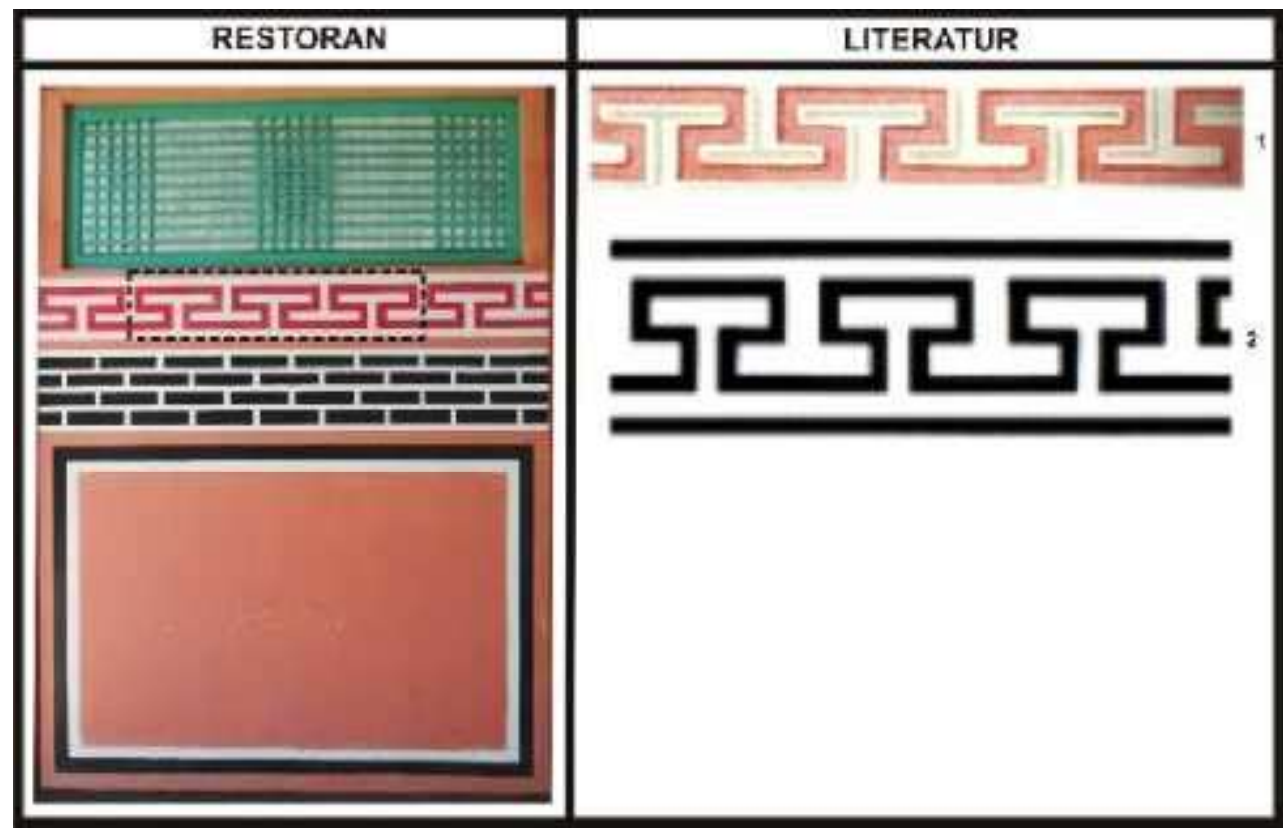

Gambar 13 Ornamen Hui Fasad Restoran Dae Jang Geum

Sumber : Survey lapangan 2015 (kiri), Lang, 2004 :252 (1), www.lifeinkorea.com/culture/patterns/paterns.cfm (2)

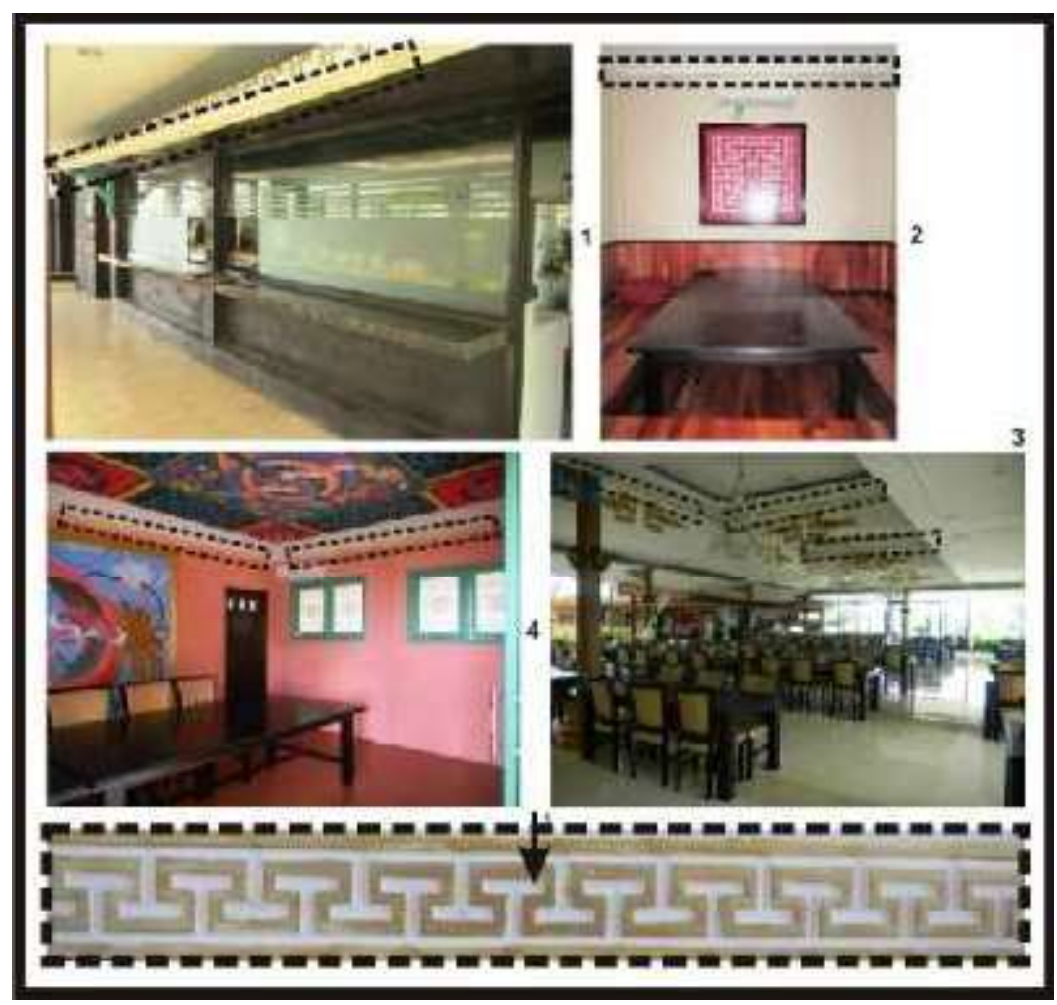

Gambar 14 Ornamen Hui pada Restoran Dae Jang Geum Sumber : Survey lapangan 2015 


\section{Ikonografi}

Ornamen ini melambangkan tak terbatas dan kesatuan.

\section{Ikonologi}

Dalam Korea simbol ini disebut Yang berarti mewakili alat kelamin laki-laki. Ketika simbol digabungkan, itu berarti kemakmuran bagi keturunan dan anak-anak. Ketika simbol ini di dalam kotak disebut hui yang artinya kelahiran kembali. (www.lifeinkorea.com)

\section{Kesimpulan}

Berdasarkan penelitian yang telah dilakukan terhadap restoran Dae Jang Geum Yogyakarta, maka dapat disimpulkan bahwa Dae Jang Geum menerapkan konsep Istana Korea yang tercermin dari arstektural bangunan, ornamen dan tata ruangnya. Ornamen tersebut diterapkan pada elemen pembentuk ruang dan aksesoris. Ornamen yang terdapat pada restoran Dae Jang Geum meliputi dancheong, bunga lotus, aprikot Jepang, phoenix, naga, harimau, ikan kayu, bebek mandarin, angsa liar dan hui.

Ornamen bebek mandarin dan aprikot jepang merupakan ornamen dari luar Korea namun sudah menjadi unsur tak terpisahkan dari ornamen Korea. Namun ada empat ornamen yang jumlahnya banyak seperti lotus, naga, phoenix dan simbol hui. Warna ornamen mengalami perubahan, lebih cerah dibandingkan dengan aslinya. Bentuknya sama dan ada pula yang berbeda dengan aslinya.

Ornamen restoran Dae Jang Geum berfungsi sebagai hiasan yang mendukung konsep istana Korea yang diterapkan pada restoran ini. Makna ikonologi berdasarkan pada pemaknaan yang terkait dengan restoran. Makna ikonografi merupakan makna sekunder dan umum yang biasanya digunakan orang Korea. Ornamen ini sebagian besar dilukis diatas kertas kemudian ditempel. Di Korea ornamen dilukis langsung diatas kayu pada bangunan yang sudah jadi. Tiang-tiang kayu pada restoran bukan kayu yang sebenarnya melainkan besi yang difinishing kayu.

\section{Kepustakaan}

Ching Francis D.K. 1985. Arsitektur, Bentuk Ruang dan Susunannya. Penerbit Erlangga. Jakarta.

Dong-uk, Kim. 2006. Palaces of Korea. Seoul : Hollym.

Gyun, Heo. 2005. Korean Temple Motifs. Korea : Dolbegae Publishers.

Korean Culture and Information Service. 2008. Guide to Korean Culture. Seoul : Korean Culture and Information Service, Ministry of Culture, Sports and Tourism.

Kyung Lee, Ja. 2005. Norigae. Seoul : Ewha Womans University Press. Lang, Gordon. 2004. 1000 Tiles. San Fransisco : Cronicle Books.

Leddy, Paul D. 1997. Practical Research Planning and Design. Ohio : Prentice Hall Inc. 
INVENSI : VOL. 1 NO. 2. DESEMBER 2016

Suh, Jae-sik. 2009. Korean Patterns. Seoul : Hollym.

www.lifeinkorea.com diakses tanggal 6 Desember 2015, jam 18:00 WIB

http://inkdancechinesepaintings.com/ diakses tanggal 6 Desember 2015, jam 17:34 WIB 